\title{
GAME-THEORETIC AND GAME-EXPERIMENTAL MODELING OF THE INTERACTION OF PARTICIPANTS OF THE TRIPLE HELIX OF INNOVATION
}

\author{
I. N. Dubina \\ Novosibirsk National Research State University (Novosibirsk, Russia)
}

This paper presents a basic formalization of university-government-industry interaction (the concept of the Triple Helix). Such formalization is based on game theory principles and methods, as well as the methods and instruments of the theory of optimal allocation of resources. The constructed models simulate the phases of R\&D, implementation and commercialization of a new project, as well as risks and uncertainty on each of these innovation stages. Based on the presented formalization, a business simulation game as a game-experimental model was developed and tested. The paper demonstrates that game-theoretic and optimal resource solutions may serve as a benchmark for real interactions of the key stakeholders of innovation ecosystems of different scales.

Keywords: Triple Helix, innovation ecosystem, game theory, optimal resources allocation, game-experimental model, business simulation game.

\section{ТЕОРЕТИКО-ИГРОВОЕ И ЭКСПЕРИМЕНТАЛЬНО-ИГРОВОЕ МОДЕЛИРОВАНИЕ ВЗАИМОДЕЙСТВИЯ УЧАСТНИКОВ «ТРОЙНОЙ ИННОВАЦИОННОЙ СПИРАЛИ»}

\author{
И.Н. Дубина \\ Новосибирский национальный исследовательский государственный университет \\ (Новосибирск, Россия)
}

В статье представлены формализованные модели отношений «университет — государство — бизнес» в контексте концепции тройной инновационной спирали. Формализация осуществлена на основе принципов и методов теории игр и теории оптимального распределения ресурсов. Предложенные модели представляют этапы разработки и коммерциализации новых проектов с учетом неопределенности и рисков, возникающих на каждом этапе. На основе результатов проведенной формализации разработана и протестирована деловая управленческая игра как экспериментально-игровая модель взаимодействия представителей науки, государства и бизнеса. В статье показано, что решения, полученные на основе методов теории игр и теории оптимального распределения ресурсов, могут служить ориентиром для принятия решений в реальных взаимодействиях ключевых участников инновационных систем различного уровня.

Ключевые слова: тройная инновационная спираль, инновационная система, теория игр, теория оптимального распределения ресурсов, экспериментально-игровая модель, деловая управленческая игра.

I ntroduction. Recently, "innovation" is one of the most popular words, both in developed and emerging economies. However, in many cases, especially in economies-in-transition, it remains to be used just as a word, not an action. One of reasons of this situation is a problem of weakly functioning innovation ecosystems which consist of such key stakeholders like government, universities and research centers, industries, investors, innovation consumers, and others.

So, the key question in this context is as follows: How can and should innovation ecosystem stakeholders effectively interact in order to produce new and right ideas and successfully commercialize them under risks and uncertainty of social and natural environment? 
Looking for a way to analyze the interactions of innovation ecosystem stakeholders, we apply some formal methods. This paper presents an attempt to formalize the concept of the university-government-industry interactions as a prototype of an innovation ecosystem. Such formalization is based on both conceptual elements of institutional economics, innovation economics and management, and formal game-theoretic principles, approaches, methods and mathematical models, as well as the methods and instruments of the theory of optimal allocation of resources.

Game Theory that officially started with the canonical book of J. von Neumann and O. Morgenstern (1944) can be defined as a logical and mathematical theory of strategic decision making under competition, risk and uncertainty; a theory of optimal and effective rational behavior; or a theory of compromises and conflict resolution (Dubina, 2013).

In particular, this paper introduces a new game-theoretic model that was designed with a goal to educate, simulate and analyze how the main innovation stakeholders (government, universities, and industries) can and should multilaterally interact through a non-linear and multistage communication in order to reach a systemic compromise (Algazin, 2009) of their interests, objectives and behaviors in an innovation and entrepreneurship ecosystem and social, political, economic and natural environment fraught with risk and uncertainty. Early versions of this paper have been presented at the IJAS 2015 conferences in Malta and Barcelona (Dubina, 2015).

The Conception of the Triple Helix of Innovation and an Innovation Ecosystem.
The basic conceptual and contextual framework for this work is the concept of the Triple Helix of university-industry-government relationships (Etzkowitz and Leydesdorff, 1995). This concept accents a more prominent role for the university in the production, transfer and application of knowledge. This way, a classical understanding of a university as a knowledge creator and transmitter is added with a concept of an Entrepreneurial University that also actively promotes knowledge in a society and puts knowledge to use in the interaction with other innovation actors and stakeholders. Entrepreneurial universities also have an enhanced capacity to generate technology that has changed their position, from a traditional source of human resources and knowledge to a new source of technology generation and transfer. In the Triple Helix conception, Government also acts as a public entrepreneur and venture capitalist, in addition to its traditional regulatory role in setting the rules of the game (Ranga and Etzkowitz, 2013).

We consider this game as a prototype of an innovation ecosystem which could be extended to more complex systems with more categories of participants, e. g., investors, comsumers, etc. As an example, the concept of the Triple Helix has been further developed toward the Quadruple Helix (Carayannis and Campbell, 2009) by adding "civil society" (citizens) as the fourth helix and the Quintuple Helix (Figure 1) that adds an Environment as a challenge and driver for innovation (Carayannis, Barth and Campbell, 2012). Such development of the initial conception of the Triple Helix concept leads toward to the N-tuple Innovation Helix conception (Park, 2014).

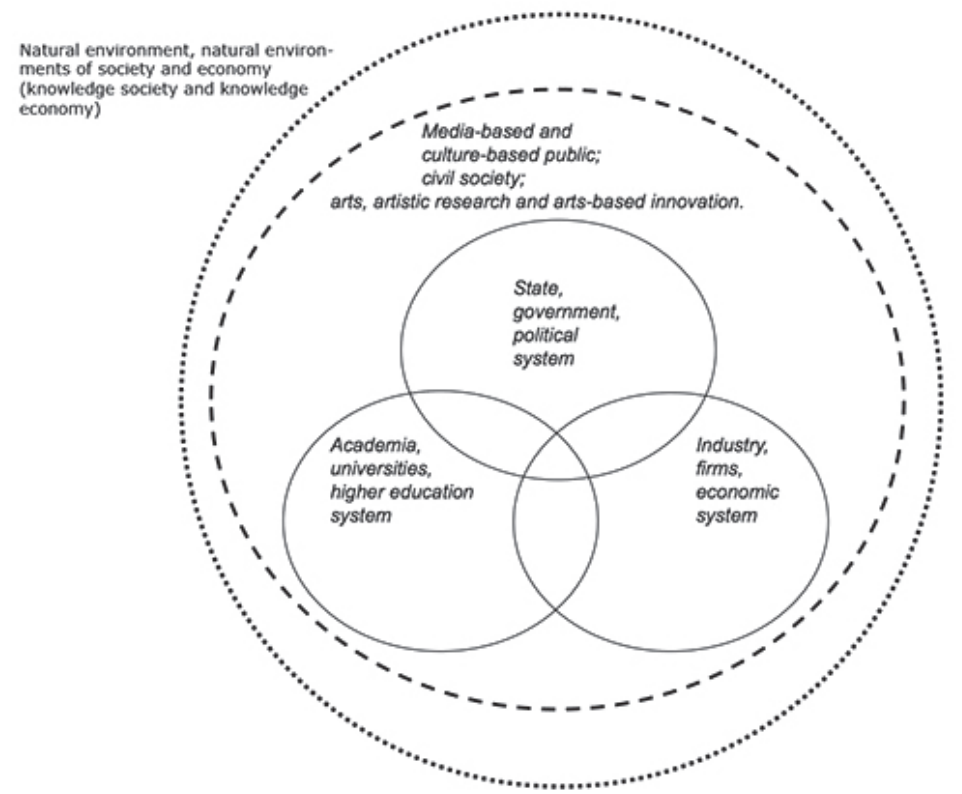

Source: Carayannis, Barth and Campbell, 2012

Figure 1. The concept of the Quintuple Innovation Helix 
In different economies, the roles of different "innovation helix" actors also differ, as well as general strategies for innovative development. For example, in Russia, China, some Central Asian, Latin American and Eastern European countries, government plays a leading role, driving academia and industry (Ranga and Etzkowitz, 2013). Such an interaction configuration defines a dominated "top to bottom" innovation strategy. In the US and many Western European countries, there is a laissezfaire configuration, characterized by a limited state intervention in the economy and a limited control over universities which are more active in initiating social, political, economic and technological innovation, with industry as a driving force for innovation (a "bottom-top" innovation strategy). Such a difference in economic and innovation models requires making specifications of a game respectively to a kind of the economy.

In any case, the main stakeholders of an innovation ecosystem have to interact on different stages and phases, like a venture project development (R\&D) phase, a new project implementation phase, and a new product commercialization phase. Each of these phases is connected with risks and uncertainty. So, a game model should represent and simulate the interaction on all of these phases under risk, uncertainty and unpredictability.

A basic game-theoretic model. This game is based on our previous studies of game-theoretic models for organizing innovative activities (Dubina, 2013) and has been designing with pursuing several goals and objectives, depending on the game "maturity". First of all, it is an educational goal, namely teaching and training possible strategies and ways of the interaction of the main innovation stakeholders (government, universities, and industries); game-theoretic principles of optimal strategic and tactical decision-making; the influence of uncertainty and risk on decision-making of the stakeholders.

The second goal relates to a next stage of the model development and it has an analytical character. This game can be used to identification, systematization and analysis of stable patterns in the interactions and outcomes of the game players.

The third main goal of designing this game relates to conditional forecasting and policy support by predicting a change direction of the players' behavior after certain interventions.

Generally, this game assumes that:

- there are several R\&D projects to be developed and implemented which are characterized with different costs and expected outcomes;

- all players have different resources to invest in $\mathrm{R} \& \mathrm{D}$ and innovation;
- University initiates R\&D projects and allocate some resources for the selected project (Stage 1);

- Government supports and invest in some initiated R\&D project (Stage 2);

- Industry chooses projects for development, investment and implementation (Stage 3).

Formally, this game is a 3 stage dynamic game with the inputs as follows:

- $n=3$ is a number of players;

- $R_{i}$ is amount of resources available to player $i$; $i=1, \ldots, n$;

- $m$ is a number of venture projects available in the game;

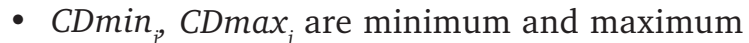
cost of the development of project $j ; j=1, \ldots, m$;

- CImin $_{j}$, CImax $_{\mathrm{j}}$ are minimum and maximum cost of the implementation of project $j$;

- $E R_{j}$ is the expected output (revenue) from project $j$;

- $\alpha$ is a parameter of interest (yield) of investing in a standard (no-risk) project.

From a game-theoretic point of view, there is also such a player as "Nature" that brings risks of the project development and implementation to the game, as well as uncertainty of players' payoffs and game outcomes. This game simulates risks and uncertainty at all the considered phases using random variables $(\mu, \varphi, \xi)$.

This game is formalized as a multiple reciprocal principal-agent model as follows.

Players' actions:

- $X_{i j}$ is fund provided by player $i$ for the development of project $j ; i=1, \ldots, n ; j=1, \ldots, m ; \sum_{i} X_{i j} \leq R_{i}$.

- $Y_{i j}$ is fund provided by player $i$ for the implementation of project $j ; i=1, \ldots, n ; j=1, \ldots, m+1$, where $Y_{i m+1}$ is fund invested in a standard (norisk) project by player $i$.

Game outcomes:

- $F D_{j}=\sum_{i} X_{i j}(j=1, \ldots, m)$ is fund collected for project $j$ at Stage 1 ;

- $p_{j}=\left(F D_{j}-C D \min _{j}\right) /\left(C D \max _{j}-C D \min _{j}\right)$ $(j=1, \ldots, m)$ is probability of successful development of project $j, 0 \leq p_{j} \leq 1$.

- $\mu_{j}$ is a random variable with uniform distribution (e. g., it can generated by MS Excel RAND () function), $0 \leq \mu_{j} \leq 1$. If $\mu_{j} \leq p_{j}$, project $j$ is successfully realized (developed) and can potentially bring some outcome to the investor. If $\mu_{j}>p_{j}$, the project is not developed and the investor gets nothing from it.

- $F I_{j}=\sum_{i} Y_{i j}(j=1, \ldots, m)$ is fund collected for project $j$ implementation;

- $q_{j}=\left(F I_{j}-C I m i n_{\mathrm{j}}\right) /\left(\operatorname{CImax}_{j}-\operatorname{CImin}_{j}\right)(j=1, \ldots$, $m$ ) is probability of successful development of project $j, 0 \leq q \leq 1$. 
- $\varphi j$ is a random variable generated by RAND (), $0 \leq \varphi_{j} \leq 1$. If $\varphi_{j} \leq q_{j}$, the project is successfully realized (implemented) and bring some revenue to the investor. If $\varphi_{j}>p_{j}$, the project is not implemented and the investor gets nothing from it.

- $\xi_{j}$ is a random variable which characterizes commercial success of an implemented project and it can be generated, e. g., by MS Excel RAND () or NORMDIST (...) functions.

- $R R_{j}, j=1, \ldots, m$, is real outcome / revenue gained from project $j$ and it may differ from expected outcome / revenue $\left(E R_{j}\right)$. If $\xi_{j}$ is generated by RAND (), $0 \leq \xi_{j} \leq 1$, real outcome can be calculated, for example, as follows:

$$
R R_{j}=E R_{j}\left(1.5-\xi_{j}\right) .
$$

So, in this case, real outcome may differ from the expected outcome $50 \%$ both sides. This rule can be conventionally changed before the game starts. For example, if $R R_{j}=E R_{j}\left(1.25-\xi_{j} / 2\right)$, a real outcome may differ from the expected outcome $25 \%$ both sides.

- $N R_{i}=Y_{i m+1}(1+\alpha)(i=1, \ldots, n)$ is revenue of player $i$ from investment in a standard (no-risk) project;

- $T R I=\sum_{j} R R_{j}(j=1, \ldots, m)$ is total real revenue gained from the venture projects (VDP);

- $T R=T R I+\sum_{i} N R_{i}(i=1, \ldots, n)$ is total revenue in this game (GDP).

Based on this formalization, all players' objective functions and payoffs in this basic game can be identified as follows:

- University: $U_{U n i}=\max \sum_{i j}\left(X_{i j}-X_{1 j}\right)$ (maximization of funds collected for developed projects by a choice of $X_{1 j}$ values controlled by Universities);

- Government: $U_{G o v}=\max \left\{\sum_{i j} p_{j}\left(X_{i j}\right) q_{j}\left(Y_{i j}\right) E R j+\right.$ $\left.\sum_{i} N R_{i}\left(Y_{i m+1}\right)\right\}$ (maximization of total expected revenue by a choice of those $X_{2 j}$ and $Y_{2 j}$ values which are controlled by Government);

- Industry: $U_{\text {Ind }}=\max \left\{\sum_{j} p_{j}\left(X_{i j}\right) q_{j}\left(Y_{i j}\right) E R j+\sum_{i} N R_{3}\right.$ $\left.\left(Y_{3 m+1}\right)-X_{3 j}-Y_{3 j}\right\}$ (maximization of Industry's profit by a choice of those $X_{3 j}$ and $Y_{3 j}$ values which are controlled by Industry);

These objective functions are to be specified for a game with certain number and character of players. Such a game-theoretic model requires further development in term of an algorithm and a software tool for solving this game (e. g., for defining a Nash equilibrium, Pareto optimal situations, and KaldorHicks improvements). This way, this model could serve a possible benchmark for real interactions of innovation stakeholders.

A business simulation game. Based on the presented formalization as well as on the experience of designing business management games, or "innovation games" (Musshoff et al., 2011; Hohmann, 2013), we developed and tested a series of business simulation games. Those games included three categories of players as indicated in the Triple Helix conception (Government-Universities-Industries) and two additional actors (Investors and Civil Societies/Innovation Consumers).

Initially, those games were tested in several student groups in Altai State University (Russia). We have piloted a business management game (called "Lab to Industry") that simulated the interaction of several groups really representing such categories of innovation stakeholders like Government, Universities, Industries, and Investors in Moscow State Technological University and Skolkovo School of Management (Moscow, May 18-20, 2015).

As a particular result, this game has clearly demonstrated a huge intercommunication and interunderstanding gap between the main innovation stakeholders (government, universities, industries and investors) because of their unwillingness and inability of searching for a compromise. And that seems to be a systemic problem not just for Russia, but also for many other economies in transition.

Such a game really helps to better understand motives, interests, possible strategies and ways of the interaction of the main innovation stakeholders and may serve as an instrument of developing mutual understanding and compromises. Recently, we have started replicating this game in Russian universities, local government and businesses, "innovation fairs", "innovation saloons", etc.

Optimal Resource Allocation Theory as a benchmark. Another possible benchmark could be a case when all the stakeholders have agreed to act as a single decision-maker for allocating their resources in the most effective way. That case would be equivalent to a canonical approach of the transportation theory (optimal allocation of resources) developed by L. Kantorovich. As a particular case, such an optimization problem can be formalized as follows.

- Objective function: $\max \left\{\sum_{j} p_{j}\left(X_{i j}\right) q_{j}\left(Y_{i j}\right) E R j+\sum_{i} N R_{i}\right.$ $\left.\left(Y_{i m+1}\right)\right\}$ (maximization of total expected revenue by a choice of $X_{i j}$ and $Y_{i j}$ values);

- Constrains: $\sum_{j}\left(X_{i j}+Y_{i j}\right)+Y_{i m+1} \leq R_{i j} ; p_{j} \leq 1 ; q_{j} \leq 1$; $i=1, \ldots, n, j=1, \ldots, m$.

This optimization problem can be solved, for example, with the tools realized in MS Excel Solver. A benchmark for game outcomes can be defined this way.

An example of a contrast of a decision-making in a group interaction within the conducted simulation game and an application of this method for $10(j=1, \ldots$, $10)$ venture projects and a non-risk project $(j=11)$ is presented by Figures 2 and 3. The total resources and investments in the both cases were 48 units, while the total revenue and profit for the first case were 94 and 46 units correspondingly, and the same values for the second case were 136 and 88 units correspondingly. 


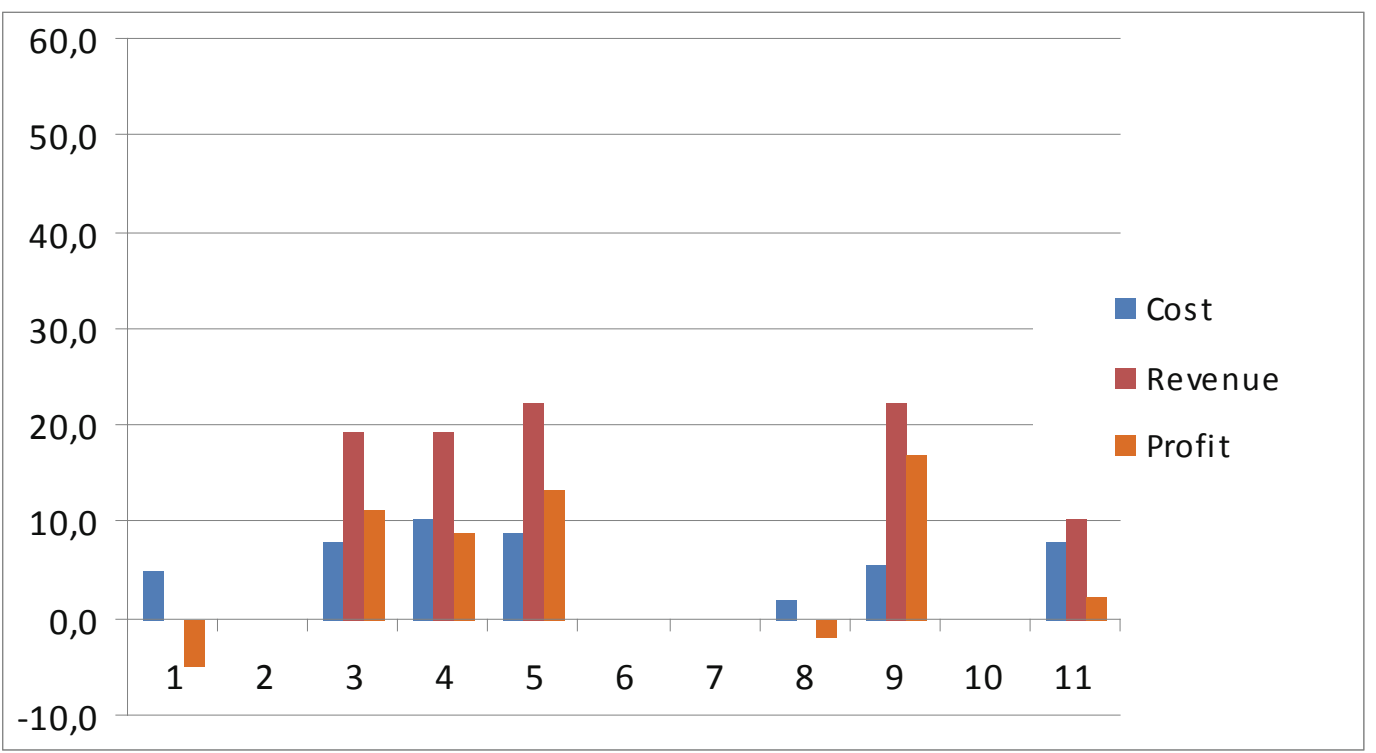

Figure 2. Distribution of resources and outcomes among the projects in the simulation game

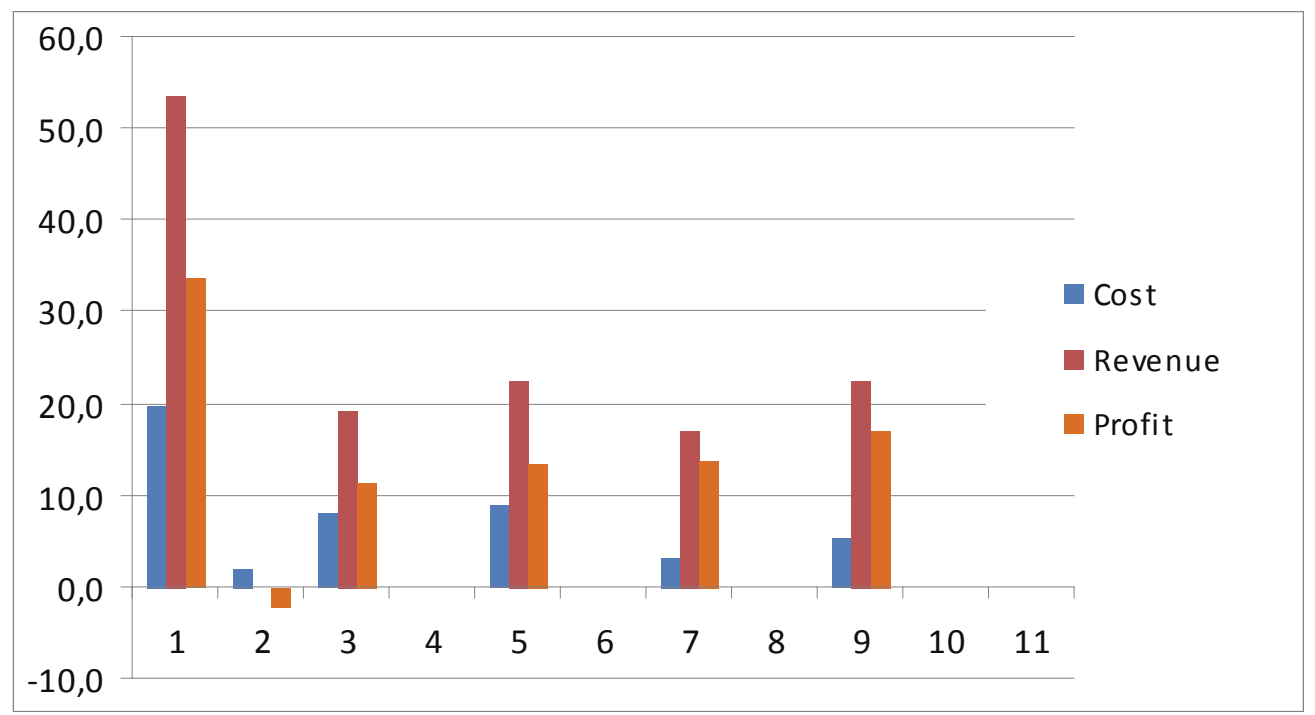

Figure 3. Distribution of resources and outcomes among the projects according to the benchmark

Conclusion. Due to a rather sophisticated character of a real innovation ecosystem, the interaction of its active elements (e. g., government, universities, industries, and investors) is very complicated. So, in this complex, dynamic and non-linear landscape of public-private collaboration and competition, gametheoretic perspectives and other formal approaches can be powerful tools for theory, policy, and practice, allowing dealing with some related challenges and opportunities. The suggested basic model of a multilevel hierarchical game can be an initial platform for further developing a theoretical framework based on the Triple Helix conception.
The designed simulation game may serve as an empirical platform for analysis and support of decisionmaking for innovation policymakers and practitioners. At the same time, a formal mathematical model of the interaction of the key innovation stakeholders may contribute to a general theoretical framework for Innovation Economics and Management. In particular, the game-theoretic solutions regarding the optimal strategies of the key stakeholders of an innovation ecosystem may serve as a benchmark for their real interactions. 


\section{REFERENCES}

1. Algazin, G. I. (2009) Models of systemic compromise in socio-economic research. Barnaul (in Russian).

2. Carayannis, E. \& Campbell, D. (2009) Mode 3" and "Quadruple Helix": toward a 21st century fractal innovation ecosystem, International journal of technology management, 46 (3-4), 201-234.

3. Carayannis, E. G., Barth, T. D., \& Campbell, D. F. J. (2012) The Quintuple Helix innovation model: global warming as a challenge and driver for innovation, I, 1 (2), 1-12.

4. Dubina, I. N. (2013) Game-Theoretic Models for Organizing creativity and innovation in firms. Barnaul (in Russian).

5. Dubina, I. N. (2015) Game theory and business simulation game approaches to innovation ecosystem analysis, International Journal of Arts and Sciences, 08 (04), 45-56.

6. Etzkowitz, H. \& Leydesdorff, L. (1995) The Triple Helix: University — Industry — Government relations a laboratory for knowledge based economic development, EASST Review, 14 (1), 14-19.

7. Hohmann, L. (2013) Innovation games: Creating Breakthrough Products Through Collaborative Play, Boston, MA, Addison-Wesley.

8. Musshoff, O., Hirschauer, N. \& Hengel, P. (2011) Are business management games a suitable tool for analyzing the boundedly rational behavior of economic agents? Modern Economy, 2, 468-478.

9. Ranga, M. \& Etzkowitz, H. (2013) Triple Helix systems: analytical framework for innovation policy and practice in the Knowledge Society, Industry and Higher Education, 27 (4), 237-262.

10. Park, H. W. (2014) Transition from the Triple Helix to N-Tuple Helices? An interview with Elias G. Carayannis and David F. J. Campbell". Scientometrics, 99, 203-207.

Поступила в редакцию: 16 апреля 2019 г. Принята к печати: 21 мая 2019 г. 